\title{
Glucocorticoids reduced short-term treatment failure in exacerbations of chronic obstructive pulmonary disease
}

Niewoehner DE, Erbland ML, Deupree, et al for the Department of Veterans Affairs Cooperative Study Group. Effect of systemic glucocorticoids on exacerbations of chronic obstructive pulmonary disease. N Engl J Med 1999 Jun 24;340:1941-7.

QUESTION: In patients who are hospitalised with exacerbations of chronic obstructive
pulmonary disease (COPD), do glucocorticoids reduce the rate of first treatment failure?

Design

Randomised (allocation concealed*), blinded (clinicians and patients), ${ }^{*}$ placebo-controlled trial with follow-up at 1,3 , and 6 months.

\section{Setting}

25 US Veterans Affairs medical centres.

Patients

271 patients (mean age 68 y, 99\% men, 83\% white) admitted to hospital with COPD. Inclusion criteria were age $\geq 50$ years, history of $\geq 30$ pack-years of smoking, and $\mathrm{FEV}_{1} \leqslant 1.5 \mathrm{l}$ or inability to have spirometry because of dyspnoea. Exclusion criteria were asthma, recent use of study drugs, or expected survival $<1$ year.

\section{Intervention}

Patients received broad-spectrum antibiotics for 1 week and inhaled $\beta$-adrenergic agonist, ipratropium bromide, and triamcinolone acetonide for 6 months. Medications other than study drugs could be used. Patients were allocated to either 8 or 2 weeks of treatment $(n=80$ each) or to placebo $(\mathrm{n}=111)$. 8-week treatment was intravenous methylprednisolone, $125 \mathrm{mg}$ every 4 hours for 72 hours, and then oral prednisone, $60 \mathrm{mg} /$ day with tapering to day 57 . The 2 -week treatment was identical except that tapering stopped at day 15 .

\section{Main outcome measure}

First treatment failure (death, need for intubation and mechanical ventilation, readmission for COPD, or intensification of drug therapy).

\section{Main results}

Data from the active drug groups were combined because 8 -week treatment was not superior to 2-week treatment. The rate of treatment failure was lower in the active drug groups than in the placebo group at 1 month and 3 months (table) $(p=0.04$ for both groups using the log-rank test [survival data]) but not at 6 months $(51 \% v$ $54 \%, \mathrm{p}=0.6)$. Patients in the active drug groups spent fewer days in the hospital $(8.5 v 9.7 \mathrm{~d}, \mathrm{p}=0.03)$ and had a higher $\mathrm{FEV}_{1}$ at days 1,2 , and $3(\mathrm{p}<0.05)$. Mortality rates did not differ $(8.1 \%$ v $9.9 \%, \mathrm{p}=0.6)$. Hyperglycaemia severe enough to warrant treatment was higher in the active drug group $(15 \% v 4 \%, \mathrm{p}=0.002)$.

D E Niewoehner,

Pulmonary Section

(111N), Veterans

Affairs Medical Center,

1 Veterans Drive,

Minneapolis, $M N$

55417, USA. FAX

612-727-5634.

Treatment failure for systemic glucocorticoids v placebo for exacerbations of chromic obstructive pulmonary disease†

\begin{tabular}{lllll} 
Time & Glucocorticoids & Placebo & RRR (95\% Cl) $\neq$ & NNT (Cl) \\
1 month & $23 \%$ & $33 \%$ & $31 \%(-2$ to 53$)$ & 10 (5 to infinity) \\
\hline 3 month & $37 \%$ & $48 \%$ & $23 \%(-3$ to 42$)$ & 9 (4 to infinity) \\
\hline
\end{tabular}

†Abbreviations defined in glossary; RRR, NNT, and Cl calculated from data in article.

$\ddagger$ Point estimates somewhat underestimate the survival analysis reported in the article and abstract text.

\section{Conclusion}

Systemic glucocorticoids reduced the rate of first treatment failure in patients hospitalised with exacerbations of COPD.

*See glossary.

\section{COMMENTARY}

Clinicians frequently use systemic corticosteroids to treat exacerbations of COPD. The underlying evidence has been modest, and guidelines have given only qualified support. ${ }^{1} \mathrm{~A}$ study by Davies and colleagues ${ }^{2}$ and this study by Niewoehner and colleagues change this by showing a clinically important benefit from systemic corticosteroids in exacerbations of COPD. Both trials reduced hospital stay by about 2 days. Niewoehner and colleagues found that corticosteroids reduced first treatment failure. Davies and colleagues showed a benefit with a lower daily steroid dose $(30 \mathrm{mg})$ than that of Niewoehner and colleagues $(60 \mathrm{mg})$. 2 weeks of treatment was beneficial, whereas 8 weeks was not necessarily better.

Both studies showed an improvement in airway obstruction, which could occur by direct effects on mucosal edema, mucus secretion, or airway inflammatory cells. This finding implies that corticosteroid-responsive airway inflammation may occur in exacerbations of COPD.

Other issues relating to the use of corticosteroids for exacerbations of COPD need clarification: what route? For how long? Should treatment be tapered or stopped abruptly? Similar issues surround the use of corticosteroids for exacerbations of asthma, and in general, a simple oral regimen is adequate, usually 30 to $50 \mathrm{mg}$ /day abruptly ceasing after 14 days.

The treatment is not without risk. Patients with COPD who received systemic glucocorticoids had increased hyperglycaemia. Other studies have shown increased risks for secondary infections, cataracts, vertebral fractures, and myopathies. ${ }^{3}$ Clinicians can be reassured in their continued use of oral prednisone for exacerbations of COPD. Evidence about stopping may be just as important as evidence about starting. John Hunter Hospital Newcastle, New South Wales, Australia

1 The COPD Guidelines Group of the Standards of Care Committee of the BTS. Thorax 1997:52(suppl 5):S1-28.

2 Davies L, Angus RM, Calverley PM. Lancet 1999;354:456-60. McEvoy CE, Niewoehner DE. Chest 1997;111:732-43.
Peter G Gibson, MBBS 